\title{
Correspondence
}

\section{Death from the oculocardiac reflex}

To the Editor:

I wish to congratulate Drs. Arndt and Stock for their interesting and informative article on the clinical importance of the diving reflex in patients under general anaesthesia.' From a simple clinical observation they have educated their colleagues about the potentially serious clinical consequences of cold $\left(<20^{\circ} \mathrm{C}\right)$ ocular irrigation.

However, they state in their article that "deaths from arrhythmia due to the oculocardiac reflex are well known." Furthermore, they reference this important point. ${ }^{2}$ To our knowledge there are no known references in the literature of deaths directly attributable to the oculocardiac reflex, ${ }^{3}$ including the references cited by Drs. Arndt and Stock. This may represent deficiencies in literature cataloguing, literature search strategies, a lack of recognition of a cause and effect relationship in decades past when electrocardiographic monitoring was virtually non-existent, or simply failure to report such cases. This does not detract from the importance of the observation made by Drs. Arndt and Stock.

However, authors have an obligation to reference carefully important points in their manuscript. ${ }^{4}$

Scott A. Lang MD FRCPC

Michael Van der Wal MB ChB FRCPC

Department of Anaesthesia

University of Saskatoon

\section{REFERENCES}

1 Amdt GA, Stock MC. Bradycardia during cold ocular irrigation under general anaesthesia: an example of the diving reflex. Can J Anaesth 1993; 40: 511-4.

2 Katz RL, Bigger IT. Candiac arrhythmias during anaesthesia and operation. Anesthesiology 1970; 33: 193-212.

3 Lang S, Lanigan DT, van der Wal M. Trigeminocardiac reflexes: maxillary and mandibular variants of the oculocardiac reflex. Can J Anaesth 1991; 38: 757-60.

4 Biebuyck JF. Concerning the ethics and accuracy of scientific citations (editorial). Anesthesiology 1992; 77: 1-2.

\section{$R E P L Y$}

We would like to thank Drs. Lang and Van der Wal for their comments on our paper on the diving reflex. Our paper was prompted by our clinical experience and that of our colleagues during the use of cold ocular irrigants. In the case report, we found a cold ocular irrigant of less than $20^{\circ} \mathrm{C}$ could produce bradycardia in an elderly patient. We initially felt the diving reflex occurring under general anaesthesia was unique; however, upon discussing this case with colleagues, both at the University of Wisconsin and Emory University many anaesthetists had encountered similar episodes while either the eye or nose was being irrigated with cold solutions. Because we were able to document the circumstances concerning an episode of bradycardia during irrigation of the eye during surgery, we felt a case report was warranted.

We wish to respond to our statement from the discussion, "death from arrythmias due to the ocular cardiac reflex are well known." Our common practice during ophthalmic surgery is to beware of the ocular cardiac reflex and take measures either to prevent or treat it. In Katz and Bigger,' we chase an article dealing primarily with cardiac arrythmias under general anaesthesia. However, on close scrutiny, when one examines the literature, there are specific case reports where either lethal arrythmias and/or death have been attributed to the ocular cardiac reflex. In the paper entitled, "Cardiac arrest during strabismus surgery," by Drs. Sorenson and Gilmore, ${ }^{2}$ a three-yearold girl experienced a cardiac arrest during resection of a medial rectus muscle. This arrest was attributed to the ocular cardiac reflex and tension applied to the medial rectus muscle. In this case, the patient was successfully resuscitated by external cardiac massage. There is also a report by Drs. Mallinson and Coombes. ${ }^{3}$ In this report, a previously healthy three-year-old boy experienced cardiac arrest during transsection of the lateral rectus muscle. The patient could not be resuscitated despite the use of open cardiac massage and cardiac defibrillation. The paper attributed the patient's death to the ocular cardiac reflex. While death from the ocular cardiac reflex is uncommon today, we feel these two reports warrant our statement, "death from arrythmias due to the ocular cardiac reflex are well known."

We hope our discussion of the diving reflex will find use in the clinical practice of anaesthesia as an explanation of bradycardia during ophthalmic surgery and perhaps as a means of terminating $S V T$ in patients refractory to other measures. While death can occur due to the ocular cardiac reflex, it is uncommon today due to many factors including increased vigilance, better monitoring and knowledge of the proper therapeutic modalities.

George A. Arndt MD

University of Wisconsin, Madison

M. Christine Stock MD

Emory University

\section{REFERENCES}

1 Katz RL, Bigger JT Jr. Cardiac arrythmias during anesthesia and operation. Anesthesiology 1970; 193-212.

2 Sorenson EJ, Gilmore JE. Cardiac arrest during strabismus surgery. Am J Ophthalmol 1956; 41: 748-52.

3 Mallinson FB, Coombes SK. A hazard of anaesthesia and opthalmic surgery. Lancet 1960; 1: 574-5. 